\title{
Mental deficiency in three families with SPG4 spastic paraplegia
}

\author{
Pascale Ribaï ${ }^{1,2}$, Christel Depienne ${ }^{2}$, Estelle Fedirko ${ }^{2}$, Anne-Catherine Jothy ${ }^{3}$, \\ Caterine Viveweger ${ }^{4}$, Valérie Hahn-Barma ${ }^{5}$, Alexis Brice ${ }^{1,2,5,6}$ and Alexandra Durr ${ }^{* 1,2}$ \\ ${ }^{1}$ Department of Genetics and Cytogenetics, AP-HP, Groupe Hospitalier Pitié-Salpêtrière, Paris, France; ${ }^{2}$ INSERM 679, \\ Paris, France; ${ }^{3}$ Foyer 'Les Nalettes', Seyssins, France; ${ }^{4}$ Centre Hospitalier Spécialisé, La Charité sur Loire, France; \\ ${ }^{5}$ AP-HP, Groupe Hospitalier Pitié-Salpêtrière, Fédération des Maladies du Système Nerveux, Paris, France; \\ ${ }^{6}$ Université Pierre et Marie Curie Paris 6, Paris, France
}

Mutations and deletions in the SPG4 gene are responsible for up to $40 \%$ of autosomal dominant hereditary spastic paraplegia (HSP). Patients have pyramidal signs in the lower limbs and some present additional features including cognitive impairment such as executive dysfunction or subcortical dementia. We report 13 patients from three SPG4 families, who had spastic paraplegia associated with mental retardation $(n=1)$, extensive social dependence $(n=10)$, or isolated psychomotor delay $(n=2)$. In family FSP-698, 10 affected individuals had both HSP and mental deficiency leading to social dependence in 9 and institutionalization in 5 . The mean age at onset of spastic paraplegia was $11 \pm 20$ years, ranging from 1 to 51 years. This phenotype segregated either with a novel p.Glu442Lys mutation or the two previously described p.Arg459Thr and p.Arg499Cys substitutions in the SPG4 gene. Since two of these mutations were previously reported in families with a pure form of the disease, another genetic factor linked to SPG4 could be responsible for this complex phenotype.

European Journal of Human Genetics (2008) 16, 97-104; doi:10.1038/sj.ejhg.5201922; published online 24 October 2007

Keywords: spastic paraplegia; mental deficiency; SPG4

\section{Introduction}

Hereditary spastic paraplegias (HSP) are clinically characterized by the presence of gait spasticity, muscle weakness and increased reflexes in the lower limbs (LL). Many patients may also have sphincter disturbances and decreased vibration sense at ankles. ${ }^{1-4}$ This phenotype defines clinically pure HSP, whereas complicated forms are associated with other neurological signs such as peripheral neuropathy, mental retardation (MR), impairment of executive functions or dementia, cerebellar

*Correspondence: Dr A Dürr, Hôpital de la Salpêtrière, INSERM U 679, Bâtiment pharmacie 4è étage, Bd de l'hôpital 47, Paris 75013, France. Tel: + 331421621 82; Fax: + 331442436 58;

E-mail: durr@ccr.jussieu.fr

Received 3 April 2007; revised 25 July 2007; accepted 16 August 2007; published online 24 October 2007 atrophy, optic atrophy or non-neurological signs such as gastrooesophageal reflux.

HSP may be transmitted as autosomal dominant (AD), autosomal recessive (AR) or X-linked (XL) diseases. Autosomal dominant transmission accounts for $70-80 \%$ of all HSP. $^{5-7}$ Among the nine genes (SPG3A, SPG4, SPG6, SPG8, SPG10, SPG13, SPG17, SPG31, SPG33) and four loci (SPG9, SPG12, SPG19, SPG29) responsible for AD-HSP, SPG4 accounts for $15-40 \%$ of the families. ${ }^{1,8-10}$ SPG4 encodes a 616-amino acid named spastin, which belongs to the AAA family (ATPases associated with diverse cellular activities). The AAA domain of spastin is located in the $\mathrm{C}$ terminus of the protein between amino acids 342 and 599 . Emerging evidence suggests that spastin plays a role in microtubule dynamics ${ }^{11}$ and that mutations in the spastin gene could lead to alteration of intracellular organelles trafficking. ${ }^{12}$ All type of SPG4 mutations have been 
described, including missense, nonsense, splice-site mutations, small insertions and deletions ${ }^{9}$ as well as large exonic deletions, ${ }^{13,14}$ which strongly suggests that the pathogenic mechanism of SPG4 mutations is haploinsufficiency (ie, disease occurs once the level of functional spastin falls below a critical level). So far, genotype-phenotype studies have not revealed a clear correlation between mutation types and age at onset or disease severity. 9,15,16 The intragenic polymorphisms S44L and $\mathrm{P} 45 \mathrm{Q}$ are, however, associated with earlier age at onset. ${ }^{17-19}$

SPG4 mutations and deletions most often result in pure HSP with a mean age at onset of $29 \pm 17$ years, ranging from infancy to 76 years. ${ }^{1,9,14}$ However, complicated forms associated to variable degrees of cognitive decline, MR, epilepsy or cerebellar ataxia in addition to spasticity were described. ${ }^{20-28}$ We previously showed that carriers of SPG4 mutation had subtle executive dysfunctions, which were absent in noncarriers relatives. ${ }^{28}$ Mental retardation was reported in SPG4 patients with cerebral malformations such as dysplasia of the corpus callosum ${ }^{27}$ or congenital arachnoid cyst. ${ }^{22}$ We describe 13 patients from three SPG4 families, who have spastic paraplegia associated with mental deficiency without cerebral malformation.

\section{Patients and methods Patients}

During diagnostic screening for SPG4 mutations in 543 families with available clinical information, we identified three families in whom MR, mental deficiency or psychomotor delay was associated with spastic paraplegia and SPG4 mutations. The probands were seen at the outpatients clinic of the Department of Genetics and Cytogenetics, Salpêtrière Hospital in Paris. Their relatives who could not come to the hospital were examined by one of us at their home or in their institutions. Families FSP-698 and FSP-748 originated from different regions of France, whereas family AAR-392 originated from Morocco. Informed consent was obtained from each family member before blood sampling.

\footnotetext{
Methods

Clinical assessment Age and sign at onset were noted for each patient, according to the patient and relatives. Gait spasticity was measured with a four-point scale, with $0=$ none, $1=$ mild, $2=$ moderate and $3=$ severe. Functional impairment was assessed with a seven-points scale $(0=$ none, $1=$ no functional impairment but signs at examination, $2=$ mild, $3=$ moderate, $4=$ walking with one cane, $5=$ walking with two canes and $6=$ wheelchairbounded). Psychomotor delay was assessed when patients acquired sitting position after the age of 9 months, gait after the age of 18 months or comprehensible speech after the normal delay of 18-24 months. Social dependence was assessed when patients needed help for daily-life activities, such as finance management, self-direction, social skills,
}

home living, and so on. Mental retardation was defined by the DSM IV criteria, as having an IQ $<70$, onset before the age of 18 years and at least two of the following: limitation in self-care, home living, social skills, community use, selfdirection, health and safety, functional academics, leisure and work. ${ }^{29}$ IQ testing could be done in patients AAR-392II-1 and FSP-698-II-3 who could attend a medical centre. We could not obtain IQ testing or neuropsychological examinations in the other patients, who were examined at home or in their institutions. Previous IQ tests and neuropsychological examinations were collected for patients FSP-698-II-4 and III-2, including global cognitive efficiency testing (WAIS III, MATTIS and MMS tests), memory test (Grober and Buschke), executive tests (FAB, Wisconsin card sorting test), language, praxic and visuospatial abilities testing. Cognitive deterioration was distinguished from MR by a worsening progression.

For patients who could not attend our consultation, we collected results of available additional investigations such as cerebral magnetic resonance imaging (MRI), neuropsychological examination or electromyography (EMG). In the proband of families without autosomal dominant transmission, we performed a metabolic screening including serum amino-acid chromatography, urine organic acids chromatography, very long-chain fatty acids dosage and measurement of lysosomal enzymes activities. Search for FMR1 CGG repeat amplification, responsible for fragile $\mathrm{X}$ syndrome was performed in patients FSP-748-III-2 and FSP-698-II-3 and high-resolution karyotype in the three index patients.

Analysis of the SPG4 gene The 17 coding exons of the SPG4 gene were screened by denaturing high-performance liquid chromatography (DHPLC) in the three probands, as already described. ${ }^{30}$ Samples showing abnormal elution profiles were re-amplified from genomic DNA. Forward and reverse sequence reactions were performed with the Big Dye Terminator Cycle Sequencing Ready Reaction Kit using the same primers (PE Applied Biosystems). The sequence products were analysed on an ABI 3730 automated sequencer (PE Applied Biosystems). Three hundred European and one hundred North African controls (mostly healthy spouses of patients with neurological diseases) were tested to rule out polymorphisms in the spastin gene.

To test for a common haplotype in families with the p.Arg499Cys mutation, we selected five microsatellite markers (D2S352, D2S2203, D2S2351, D2S2325 and D2S2347) flanking the SPG4 locus. We also developed four additional intragenic SPG4 microsatellite markers, located in intron 2 (ATT10), intron 3 (TAT17), intron 4 (TAG14) and intron 9 (TG15), respectively. Finally, six SNP located in the 3'-UTR of the gene (rs7572964, rs4952252, rs4952207, rs4519572, rs4407291 and rs4530415) were genotyped. Template DNA was denatured at $94^{\circ} \mathrm{C}$ for 
$5 \mathrm{~min}$, followed by 35 cycles of amplification at $94^{\circ} \mathrm{C} 30 \mathrm{~s}$, $55^{\circ} \mathrm{C} 30 \mathrm{~s}$ and $72^{\circ} \mathrm{C} 30 \mathrm{~s}$, then by a final step of elongation at $72^{\circ} \mathrm{C}$ for $7 \mathrm{~min}$. PCR products were mixed with deionized formamide and the GENESCANTM 400HD ROX standard (Applied Biosystems) and denatured at $95^{\circ} \mathrm{C}$ for $5 \mathrm{~min}$, before analysis on an ABI 3730 automated sequencer (Applied Biosystems). Genotypes were analysed with GeneMapper 3.5 software (Applied Biosystems).

\section{Results}

\section{Clinical features}

Pedigrees of the three families are shown in Figure 1. Transmission of spastic paraplegia was dominant in families FSP-698 and FSP-748. In family AAR-392, the proband was an isolated case. The mean age at examination was $40.5 \pm 13.1$ years, ranging from 22 to 63 years (Tables $1 \mathrm{a}$ and $\mathrm{b}$ ). The mean age at onset of spasticity was $11.0 \pm 19.7$ years, ranging from 1 to 51 years. Six patients could not remember the age when they started having difficulties in walking, but noted that it was during childhood $(n=3)$, adolescence $(n=1)$ or as long as they could remember $(n=2)$.
Gait spasticity was severe in eight patients, moderate in three and mild in two. Functional motor impairment varied from none to severe, with four patients using a wheelchair. All patients presented increased reflexes in the LL, 77\% (10/13) in upper limbs (UL). Plantar reflexes were extensor in all symptomatic patients. Vibration sense at ankles was decreased in nine patients. Seven patients suffered from sphincter disturbances.

Cerebral MRI performed in five patients was normal $(n=2)$, showed cortical and subcortical atrophy $(n=3)$ (Figure 2 ) or white matter abnormalities $(n=1)$. Medullar atrophy was present in the four patients who had medullar MRI.

\section{Cognitive features in family FSP-698}

Patient III-2 fitted with all the DSM IV criteria of MR. MR was also diagnosed in patients II-1, II-2 and II-4 who had psychomotor delay in childhood, were institutionalized and totally dependent at the time of examination.

Patients II-3, III-3 and IV-1 had psychomotor delay and were dependent for daily-life activities. Patient II-3 did not have mental retardation since his IQ was within the

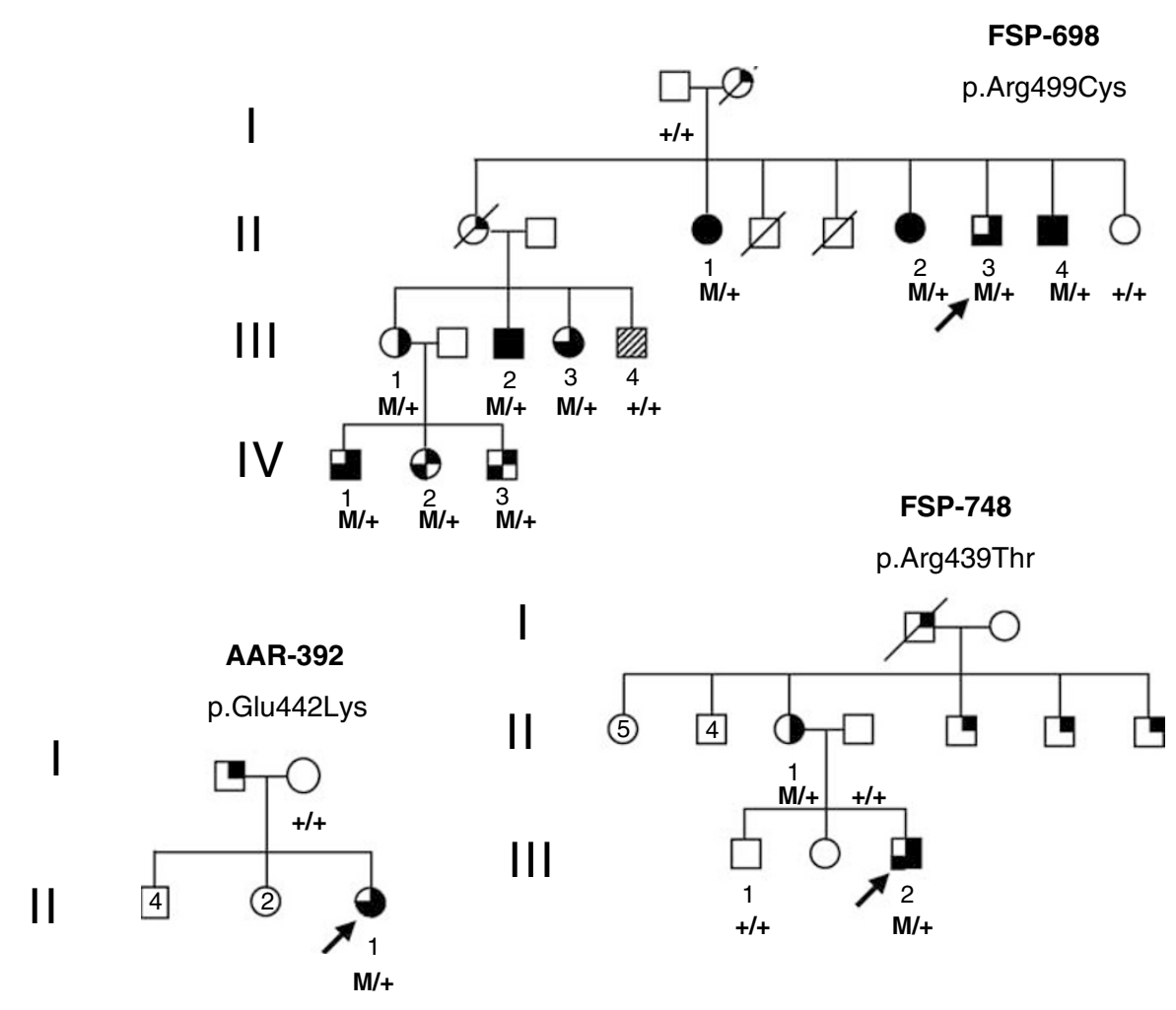

Figure 1 Pedigrees of three families with HSP and mental difficulties. Upper right black corner: spastic paraplegia. Lower right black corner: psychomotor delay (sitting position acquired after the age of 9 months, gait after the age of 18 months or comprehensible speech after 18-24 months of age). Upper left black corner: mental retardation. Lower left black corner: social dependence (help needed for daily-life activities, such as monthly finance management, self-direction, social skills, home living, etc). Hatched symbol: patient with psychotic disorder and autistic features, without pyramidal signs at examination. Numbers under the symbols: sampled and examined patient's numbers according to generations I-IV. The SPG4 mutations are indicated under the family identification number. $\mathrm{M} /+$ : heterozygote mutation, $+/+$ : homozygous wild-type alleles. 
Table 1a Clinical features of 10 patients of family FSP-698

\begin{tabular}{|c|c|c|c|c|c|c|c|c|c|c|}
\hline Patient number & $11-1$ & $11-2$ & $11-3^{\mathrm{a}}$ & $11-4$ & $I I I-1$ & $111-2$ & III-3 & $I V-1$ & $I V-2$ & IV-3 \\
\hline Age at examination (years) & 63 & 55 & 53 & 47 & 45 & 43 & 39 & 29 & 27 & 24 \\
\hline Age at onset (years) & Childhood & 51 & Adolescence & 4 & 5 & Birth & Childhood & Birth & 1 & Childhood \\
\hline Sign at onset & Stiff legs & Stiff legs & Stiff legs & Stiff legs & Stiff legs & $\begin{array}{l}\text { Never } \\
\text { acquired } \\
\text { gait }\end{array}$ & $\begin{array}{l}\text { Tip toes } \\
\text { gait }\end{array}$ & Stiff legs & Stiff legs & Stiff legs \\
\hline \multicolumn{11}{|l|}{ Neurological impairment } \\
\hline Gait spasticity & 3 & 1 & 3 & 3 & 3 & 3 & 3 & 3 & 2 & 2 \\
\hline Functional impairment & 6 & 2 & 5 & 6 & 5 & 6 & 6 & 3 & 3 & 2 \\
\hline Increased reflexes (LL) & + & + & + & + & + & + & + & + & + & + \\
\hline Increased reflexes (UL) & + & + & + & + & + & - & + & + & - & - \\
\hline Extensor plantar reflexes & Bilateral & Bilateral & Bilateral & Bilateral & Bilateral & Bilateral & Bilateral & Bilateral & Bilateral & Bilateral \\
\hline $\begin{array}{l}\text { Vibration sense alteration at } \\
\text { ankles }\end{array}$ & + & + & + & + & + & + & + & - & + & - \\
\hline Sphincter disturbances & + & + & + & + & + & + & - & - & + & - \\
\hline Psychomotor delay & + & + & + & + & + & + & + & + & - & - \\
\hline \multicolumn{11}{|l|}{ Cognitive impairment } \\
\hline Intellectual deterioration & - & + & - & + & - & - & - & - & - & - \\
\hline Institutionalized & + & + & + & + & - & + & - & - & - & + \\
\hline Help needed for daily life & Totally & Totally & Partially & Totally & None & Totally & Partially & Partially & Partially & Totally \\
\hline \multicolumn{11}{|l|}{ Additional investigations } \\
\hline $\begin{array}{l}\text { Neuropsychological } \\
\text { examination }\end{array}$ & ND & ND & IQ:100 & $\begin{array}{l}\text { Homogenous } \\
\text { impairment of } \\
\text { all intellectual } \\
\text { functions }\end{array}$ & ND & IQ:70 & ND & ND & ND & ND \\
\hline Cerebral MRI & ND & ND & $\begin{array}{l}\text { Cortical and } \\
\text { subcortical } \\
\text { atrophy, } \\
\text { nonspecific } \\
\text { WMH }\end{array}$ & $\begin{array}{l}\text { Cortical } \\
\text { atrophy }\end{array}$ & ND & $\begin{array}{l}\text { Cortical and } \\
\text { subcortical } \\
\text { atrophy }\end{array}$ & ND & Normal & ND & ND \\
\hline Medullar MRI & ND & $\begin{array}{l}\text { Medullar } \\
\text { atrophy }\end{array}$ & $\begin{array}{l}\text { Medullar } \\
\text { atrophy }\end{array}$ & $\begin{array}{l}\text { Medullar } \\
\text { atrophy }\end{array}$ & ND & $\begin{array}{l}\text { Medullar } \\
\text { atrophy }\end{array}$ & ND & ND & ND & ND \\
\hline
\end{tabular}

$\mathrm{Q}=$ Intellectual quotient, $\mathrm{ND}=$ not done, $\mathrm{WMH}=$ white matter hypersignals, $+=$ yes, $-=$ no. Functional impairment: $0=$ none, $1=$ no functional impairment but signs at examination $2=$ mild, $3=$ moderate, $4=$ walking with one cane, $5=$ walking with two canes and $6=$ wheelchair-bounded. Gait spasticity: $0=$ none, $1=$ mild, $2=$ moderate and $3=$ severe. Index patient. 
Table 1b Clinical features of three patients of families AAR-392 and FSP-748

\begin{tabular}{|c|c|c|c|}
\hline Family-patient & $A A R-392-1 I-1^{a}$ & FSP-748-II-1 & FSP-748-III- $2^{\mathrm{a}}$ \\
\hline Age at examination (years) & 30 & 49 & 22 \\
\hline Age at onset (years) & 1 & No complain & 4 \\
\hline Sign at onset & Stiff legs & & Stiff legs \\
\hline \multicolumn{4}{|l|}{ Neurological impairment } \\
\hline Gait spasticity & 3 & 0 & 2 \\
\hline Functional impairment & 4 & 1 & 3 \\
\hline Increased reflexes (LL) & + & + & + \\
\hline Increased reflexes (UĹ) & + & + & + \\
\hline Extensor plantar reflexes & Bilateral & No & Unilateral \\
\hline Vibration sense alteration & - & + & - \\
\hline Sphincter disturbances & - & - & - \\
\hline Psychomotor delay & + & + & + \\
\hline \multicolumn{4}{|l|}{ Cognitive impairment } \\
\hline Intellectual deterioration & - & - & - \\
\hline Institutionalized & - & - & - \\
\hline Help needed for daily life & Partially & None & Partially \\
\hline \multicolumn{4}{|l|}{ Additional investigations } \\
\hline Neuropsychological examination & IQ:91 & ND & ND \\
\hline Cerebral MRI & ND & ND & Normal \\
\hline
\end{tabular}

$\mathrm{ND}=$ not done $+=$ yes, $-=$ no. Functional impairment: $0=$ none, $1=$ no functional impairment but signs at examination, $2=$ mild, $3=$ moderate $4=$ walking with 1 cane, $5=$ walking with 2 canes and $6=$ wheelchair-bounded. Gait spasticity: $0=$ none, $1=$ mild, $2=$ moderate and $3=$ severe. andex patient.
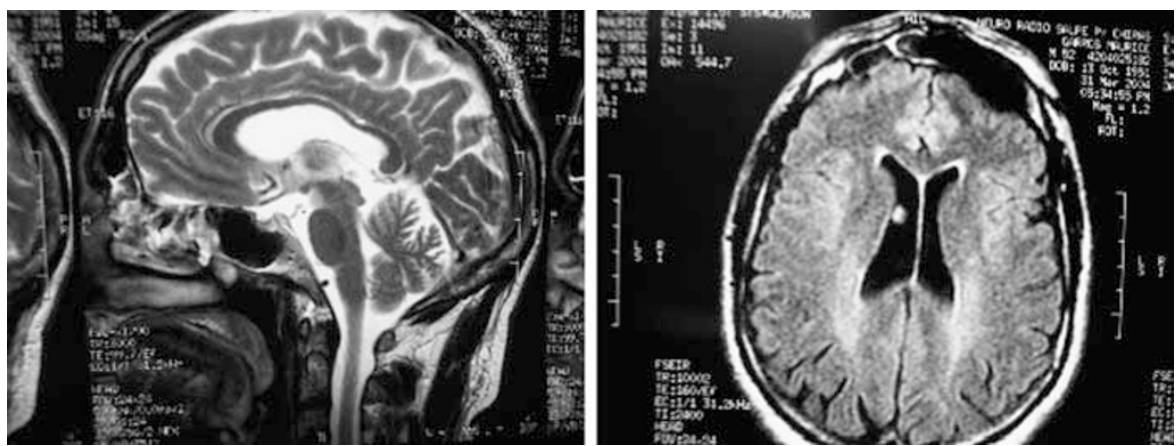

Figure 2 Cerebral MRI of patient FSP-698-II-3 at age 53 years. Sagittal and coronal cerebral pictures, showing global cortical and subcortical atrophy, as well as periventricular white matter abnormalities.

normal range (100), but he was partially dependent for daily-life activities. He lived in an institution.

Patients IV-2 and 3 were noninstitutionalized, without history of psychomotor delay, but were socially dependent.

Patient FSP-698-III-1 had isolated psychomotor delay, was not institutionalized and did not have IQ testing. Her mental status remained uncertain.

Patient III-4, unaffected for HSP, was institutionalized in a psychiatric hospital since the age of 10 years, with a diagnosis of severe psychotic disorder with autistic features. He had no language and was not tested for IQ. We considered his mental status as undetermined.

Mental deficiency was not progressive in all but two patients (FSP-698-II-2 and FSP-698-II-4), who complained about memory deterioration, since the age of 50 and 44 years, respectively.

\section{Cognitive features in family FSP-748}

Patient II-1 had increased reflexes in LL, vibration sense alteration and psychomotor delay. She was not institutionalized and did not have IQ testing. Her mental status remained uncertain.

Patient III-2 had psychomotor delay and was dependent for daily-life activities.

\section{Cognitive features in family AAR-392}

Patient II-1 had psychomotor delay and was dependent for daily-life activities. As for patient FSP-698-II-3, she had no 
mental retardation $(I Q=91)$, but mental deficiency was suggested by her social dependence. Cognitive impairment was confirmed by neuropsychological examination which showed low performances at MMS (27/30) and particularly MATTIS (126/144) tests. In addition, impairment of executive functions such as attention and verbal fluency (14/18 at the FAB) was evident. Cognitive impairment and affective immaturity were also suggested by learning difficulties as soon as in primary school, associated to introverted behavioural abnormalities. She worked in a centre for mentally disabled persons.

Her mother had a normal neurological examination at age 58 years. Her 62 years old father was reported to have cognitive and gait difficulties, but did not allow to be examined.

\section{Molecular results}

An abnormal DHPLC profile was observed in exon 13 of the proband of family FSP-698, caused by a C $>$ T substitution at position 1495 of the coding sequence. This change, which causes the p.Arg499Cys substitution, is a recurrent mutation previously described in other families with HSP. $^{9,30-32}$ In family FSP-748, an abnormal profile in exon 11 revealed the presence of the $\mathrm{c} .1376 \mathrm{G}>\mathrm{C} / \mathrm{p}$.Arg459Thr missense mutation, which has been previously reported in another HSP family. ${ }^{33}$ A novel missense mutation in exon 11 , c. $1324 \mathrm{G}>\mathrm{A} / \mathrm{p}$.Glu442Lys, was identified in the proband of family AAR-392. Glutamic acid at position 442 is located in the AAA cassette of spastin and is conserved in mammals as well as in Drosophila and Fugu. This novel mutation was not found in a large control population of 800 chromosomes. Neither the S44L nor P45Q SPG4 intragenic polymorphisms have been found in the probands of the three families.

SPG4 mutations segregated both with HSP and mental deficiency in families FSP-698 and 748. In family FSP-698, a bi-point LOD score of 3.0102 was calculated when the mental status of patients FSP-698-III-1 and 4 was considered as undetermined. The former had isolated psychomotor delay associated with HSP and the latter had autistic features without HSP. This result suggests that the p.Arg499Cys mutation in family FSP-698 is associated with a mental deficiency of variable severity, ranged from psychomotor delay to mental retardation.

The p.Arg499Cys mutation was also identified in two other families who had HSP without mental impairment (Depienne et al, in preparation). To determine whether the mutation in these two families occurred independently from that of family FSP-698 or came from a common ancestor, we genotyped seven microsatellite markers, four of which were located inside the SPG4 gene and six SNP in the patients of the three families. The results were consistent with a possible common ancestor for the two families with pure HSP, but revealed that the mutation occurred independently in family FSP-698 (Table 2).

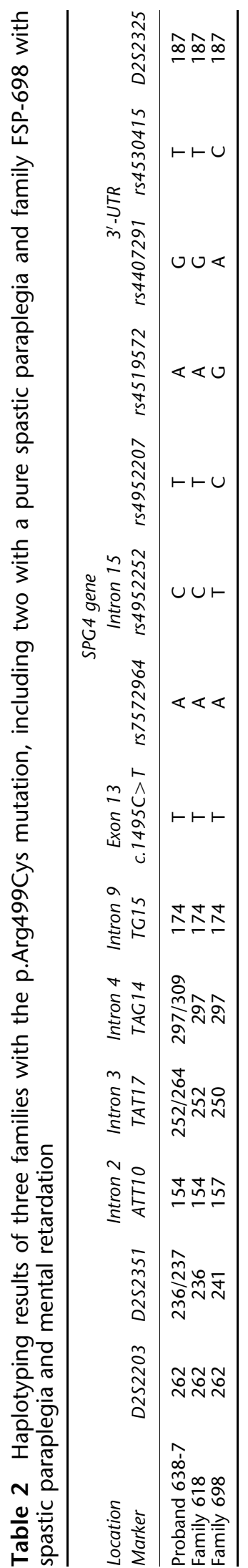




\section{Discussion}

We report 13 patients from three families with MR, mental deficiency or psychomotor delay associated to SPG4-related HSP. This is the first study that reports mental retardation or deficiency in patients with SPG4 mutations and without cerebral malformation.

Neuropsychological examination or IQ testing could be obtained for four patients only, since the others were institutionalized or could not attend a medical centre. One patient (FSP-698-III-2) fitted the DSM IV criteria for MR, three others (FSP-698-II-1, 2 and 4) were institutionalized, totally dependent and had psychomotor delay in childhood. Two patients (FSP-698-IV-2 and 3) without psychomotor delay were socially dependent in daily life, suggesting mental deficiency. The remaining seven patients had psychomotor delay in early childhood, five of whom (FSP-698-II-3, III-3, IV-1, FSP-748-III-2 and AAR392-II-1) were also dependent of relatives in daily life, suggesting the presence of intellectual difficulties and social inadaptation. Patients AAR-392-II-1 and FSP-698-II3 had an IQ slightly inferior to average, ranging from 91 to 100. Nevertheless, we used the term of 'mental deficiency' because of the extensive social dependence associated with executive dysfunction, affective immaturity, behavioural and social inadaptation.

Cognitive impairment was reported by us and others in patients with SPG4 mutations. ${ }^{20,21,23,24,26,28,34}$ Compared to the early onset in childhood leading to social dependence in adulthood observed in our patients, it was usually mild without functional impairment and limited to executive dysfunction, although it could occasionally progress to subcortical dementia. Cognitive decline may be present before the onset of spastic paraplegia. ${ }^{20,21,24}$ Mental deficiency in our patients was clearly distinct from cognitive deterioration, as it was evident since infancy and was not progressive.

Common causes of MR were excluded by metabolic screening in the proband of family AAR-392, chromosomal analyses in the three index patients and PCR analysis of the FMR1 repeat segment in two male patients (FSP-748-III-2 and FSP-698-II-3). In addition, X-linked mental retardation not related to HSP was unlikely because of the similar disease severity in male and female patients.

Mental retardation was already described in patients with SPG4 mutations, but they all had in addition cerebral malformations such as dysplasia of the corpus callosum ${ }^{27}$ or congenital arachnoid cyst. ${ }^{22}$ No malformation or other structural abnormality was found in five of our patients.

Our patients had slightly different HSP clinical characteristics compared to the previously described SPG4 patients without mental impairment. Age at onset of spasticity was earlier in our patients $(11 \pm 19.7$ versus $29 \pm 17$ years), ${ }^{9,35}$ who also presented more frequently brisk reflexes in UL (77\%), compared to $20-30 \%$ in SPG4 patients without MR. ${ }^{2,9}$ However, the proportion of patients who had increased UL reflexes increased with disease duration, ${ }^{9}$ which was longer in our patients compared to SPG4 patients without MR $(29.2 \pm 13.4$ versus $21 \pm 15$ years).

Although the p.Glu442Lys mutation found in family AAR-392 is novel, the p.Arg499Cys and p.Arg459Thr mutations were previously described in families with pure HSP and in an isolated patient with spastic paraplegia associated to dementia. ${ }^{9,30-33}$ This suggests that the SPG4 mutations in our patients are not sufficient to explain the presence of mental deficiency or psychomotor delay, but that other genetic factors could explain the phenotype. The S44L or P45Q SPG4 intragenic polymorphisms were absent in the probands of the three families. They have not been described with complicated HSP forms, but account for pure HSP forms with early age at onset.

For the LOD score calculation, two patients were considered with an undetermined clinical status for mental deficiency: (1) patient FSP-698-III-4 who did not carry the SPG4 mutation nor had spastic paraplegia. He had a psychotic disorder with autistic traits and lived in a psychiatric institution since the age of 10 years. He had no language and could not be tested for IQ to assess whether or not he was mentally retarded. (2) Patient FSP-698-III-1 had HSP and psychomotor delay in childhood. She was able to live alone without assistance, and was not tested for IQ. The LOD score reached 3.0102 in family FSP-698, suggesting a nonrandom association between HSP, SPG4 and mental deficiency of variable severity, ranging from psychomotor delay to mental retardation.

Segregation of HSP with mental deficiency in family FSP-698 argues in favour of a variant linked to SPG4, that is, located in the chromosome 2 interval shared by all the affected individuals. This hypothesis is in agreement with the finding that the p.Arg499Cys mutation in family FSP-698 occurred independently than the same mutation found in two other families with pure HSP. However, we cannot exclude that a micro-rearrangement on chromosome 2 or on another chromosome could also segregate in the 10 patients of family FSP-698 and account for the presence of mental deficiency in this family.

These findings extend the clinical spectrum of the SPG4associated phenotypes, which should be tested in patients with spastic paraplegia even with mental retardation or psychomotor delay. Additional genetic studies need to be carried out to identify all genetic factors responsible for this complicated phenotype.

\section{Acknowledgements}

$P$ Ribai received a fellowship from the Société Française de Neurologie. This study was supported by the PHRC 2003 (AOM 03059) and the VERUM Foundation. 


\section{References}

1 Durr A, Davoine CS, Paternotte C et al: Phenotype of autosomal dominant spastic paraplegia linked to chromosome 2. Brain 1996; 119: $1487-1496$.

2 Reid A: The hereditary spastic paraplegias. J Neurol 1999; 246: 995-1003.

3 Tallaksen CME, Durr A, Brice A: Recent advances in hereditary spastic paraplegia. Curr Opin Neurol 2001; 14: 457-463.

4 Fink JK: The hereditary spastic paraplegias. Arch Neurol 2003; 60: 1045-1049.

5 Harding AE: Hereditary 'pure' spastic paraplegia: a clinical and genetic study of 22 families. J Neurol Neurosurg Psychiatry 1981; 44: $871-883$.

6 Polo JM, Calleja J, Combarros O, Berciano J: Hereditary ataxias and paraplegias in Cantabria, Spain. An epidemiological and clinical study. Brain 1991; 114 (Part 2): 855-866.

7 McMonagle P, Webb S, Hutchinson M: The prevalence of 'pure' autosomal dominant hereditary spastic paraparesis in the island of Ireland. J Neurol Neurosurg Psychiatry 2002; 72: 43-46.

8 Kobayashi H, Garcia CA, Alfonso G, Marks HG, Hoffman EP: Molecular genetics of familial spastic paraplegia: a multitude of responsible genes. J Neurol Sci 1996; 137: 131-138.

9 Fonknechten N, Mavel D, Byrne P et al: Spectrum of SPG4 mutations in autosomal dominant spastic paraplegia. Hum Mol Genet 2000; 9: 637-644.

10 Meijer IA, Hand CK, Cossette P, Figlewicz DA, Rouleau GA: Spectrum of SPG4 mutations in a large collection of North American families with hereditary spastic paraplegia. Arch Neurol 2002; 59: 281-286.

11 Errico A, Ballabio A, Rugarli EI: Spastin, the protein mutated in autosomal dominant spastic paraplegia, is involved in microtubule dynamics. Hum Mol Genet 2002; 11: 153-163.

12 Tarrade A, Fassier C, Courageot S et al: A mutation of spastin is responsible for swellings and impairment of transport in a region of axon characterized by changes in microtubule composition. Hum Mol Genet 2006; 15: 3544-3558.

13 Beetz C, Nygren AO, Schickel J et al: High frequency of partial SPAST deletions in autosomal dominant hereditary spastic paraplegia. Neurology 2006; 67: 1912-1913.

14 Depienne C, Fedirko E, Forlani S et al: Exon deletions of SPG4 are a frequent cause of hereditary spastic paraplegia. I Med Genet 2007; 44: 281-284.

15 Hentati A, Deng HX, Zhai H et al: Novel mutations in spastin gene and absence of correlation with age at onset of symptoms. Neurology 2000; 55: 1388-1390.

16 Yip AG, Durr A, Marchuk DA et al: Meta-analysis of age at onset in spastin-associated hereditary spastic paraplegia provides no evidence for a correlation with mutational class. J Med Genet 2003; 40: e106.

17 Lindsey JC, Lusher ME, McDermott CJ et al: Mutation analysis of the spastin gene (SPG4) in patients with hereditary spastic paraparesis. J Med Genet 2000; 37: 759-765.

18 Svenson IK, Kloos MT, Gaskell PC et al: Intragenic modifiers of hereditary spastic paraplegia due to spastin gene mutations. Neurogenetics 2004; 5: 157-164.
19 Chinnery PF, Keers SM, Holden MJ, Ramesh V, Dalton A: Infantile hereditary spastic paraparesis due to codominant mutations in the spastin gene. Neurology 2004; 63: 710-712.

20 McMonagle P, Byrne PC, Fitzgerald B, Webb S, Parfrey NA, Hutchinson M: Phenotype of AD-HSP due to mutations in the SPAST gene: comparison with AD-HSP without mutations. Neurology 2000; 55: 1794-1800.

21 Byrne PC, McMonagle P, Webb S, Fitzgerald B, Parfrey NA, Hutchinson $\mathrm{M}$ : Age-related cognitive decline in hereditary spastic paraparesis linked to chromosome 2p. Neurology 2000; 54: $1510-1517$.

22 Orlacchio A, Gaudiello F, Totaro A et al: A new SPG4 mutation in a variant form of spastic paraplegia with congenital arachnoid cysts. Neurology 2004; 62: 1875-1878.

23 Nielsen JE, Johnsen B, Koefoed $\mathrm{P}$ et al: Hereditary spastic paraplegia with cerebellar ataxia: a complex phenotype associated with a new SPG4 gene mutation. Eur J Neurol 2004; 11: $817-824$.

24 Mc Monagle P, Byrne P, Hutchinson M: Further evidence of dementia in SPG4-linked autosomal dominant hereditary spastic paraplegia. Neurology 2004; 62: 407-410.

25 Tang B, Zhao G, Xia K et al: Three novel mutations of the spastin gene in Chinese patients with hereditary spastic paraplegia. Arch Neurol 2004; 61: 49-55.

26 Orlacchio A, Kawarai T, Gaudiello F et al: Clinical and genetic study of a large SPG4 Italian family. Mov Disord 2005; 20: $1055-1059$.

27 Alber B, Pernauer M, Schwan A et al: Spastin related hereditary spastic paraplegia with dysplastic corpus callosum. I Neurol Sci 2005; 236: 9-12.

28 Tallaksen CM, Guichart-Gomez E, Verpillat P et al: Subtle cognitive impairment but no dementia in patients with spastin mutations. Arch Neurol 2003; 60: 1113-1118.

29 American Psychiatric Association: Diagnosis and Statistical Manual of Mental disorders, 4th edn. Text revision Washington, DC: American Psychiatric Association, 2000.

30 Depienne C, Tallaksen C, Lephay JY et al: Spastin mutations are frequent in sporadic spastic paraparesis and their spectrum is different from that observed in familial cases. J Med Genet 2006; 43: $259-265$.

31 Hazan J, Fonknechten N, Mavel D et al: Spastin, a new AAA protein, is altered in the most frequent form of autosomal dominant spastic paraplegia. Nat Genet 1999; 23: 296-303.

32 Yabe I, Sasaki H, Tashiro K, Matsuura T, Satoh T: Spastin gene mutation in Japanese with hereditary spastic paraplegia. I Med Genet 2002; 39: e46.

33 Falco M, Scuderi C, Musumeci S et al: Two novel mutations in the spastin gene (SPG4) found by DHPLC mutation analysis. Neuromuscul Disord 2004; 14: 750-753.

34 Scheuer KH, Nielsen JE, Krabbe K et al: Reduced regional cerebral blood flow in SPG4-linked hereditary spastic paraplegia. J Neurol Sci 2005; 235: 23-32.

35 Durr A, Camuzat A, Colin E et al: Atlastin 1 mutations are frequent in young-onset autosomal dominant spastic paraplegia. Arch Neurol 2004; 61: 1867-1872. 